\title{
Development, Occurrence and Characteristics of Egg Capsules of the Thorny Skate, Raja radiata, in the Northwest Atlantic
}

\author{
Wilfred Templeman \\ Department of Fisheries and Oceans, Research and Resource Services \\ P. O. Box 5667, St. John's, Newfoundland, Canada A1C 5X1
}

\begin{abstract}
Data related to the egg capsules of the thorny skate, Raja radiata, gathered in 1947-72 from various parts of the Northwest Atlantic, were analyzed. The development of the capsule is described in relation to the shell gland and the passage of the egg and albumen into the capsule. The egg was present in the capsule when the latter was seven-tenths or more complete. Albumen was always present once the capsule was developed enough to hold it. Occasional complete capsules were without eggs or possessed unusually small eggs. The right capsule was typically extruded first. Capsules in various stages of development were observed to occur generally throughout the area investigated and in all months of the year. The size of the capsule and the volumes of the contained egg and albumen increased with increase in fish length and consequently were greater in skates from areas where sexual maturity began at greater lengths than in areas where sexual maturity occurred at smaller lengths.
\end{abstract}

\section{Introduction}

The egg capsule (egg case) of the thorny skate was described by Beard (1890), Williamson (1913), Nordgaard (1917), Vladykov (1936), and the structure of the wall of the capsule by Jensen $(1914,1948)$. Some information on size of the capsule of this skate in various areas was given by Jensen (1914), Nordgaard (1917), Clark (1926), Vladykov (1936), Bigelow and Schroeder (1953) and Backus (1957). However, apart from the descriptions of the capsule, the total amount of published information available is minor.

\section{Materials and Methods}

The data on egg capsules were obtained from thorny skates mainly taken in bottom-trawl catches of research vessels of the St. John's Biological Station (now called Research and Resource Services, Department of Fisheries and Oceans) from 1947 to 1972. The capsules in fresh condition were examined by the author usually in the laboratory after preservation of the fish in ice but occasionally at sea soon after the specimens were caught. The location of skate samples examined for egg capsules and the NAFO divisions of the Northwest Atlantic are shown in Fig. 1. As thorny skates from the northern part of Div. 2J were considered to be more related to those off northern Labrador and Baffin Island, Div. 2Jn and 2Js used in this paper refer to the areas of Div. $2 \mathrm{~J}$ north and south of $53^{\circ} \mathrm{N}$ respectively. Thorny skates from the north coast of Iceland were taken in the area of $65^{\circ} 48^{\prime}-66^{\circ} 31^{\prime} \mathrm{N}$ and $17^{\circ} 28^{\prime}-20^{\circ} 49^{\prime} \mathrm{W}$ at $82-161 \mathrm{~m}$.
Measurements of the median lengths of egg capsules included the velum and the greatest width included the flat lateral keels. Only complete capsules ready for extrusion were used for measurements of egg and albumen volumes and capsule weights. After the capsule was weighed, part of the convex surface was removed and the volumes of egg and albumen measured separately in water in graduated cylinders. The albumen measurement included all free albumen and as much as could be scraped from the capsule and the bases of the horns. Broken eggs were not used. Data for left and right capsules were averaged whenever both were available from the same fish. Egg capsules and contents with no egg and the one capsule with a very small egg, both shown in Table 2, were omitted from the averages. Skate lengths in this paper are total lengths, tip of snout to posterior end of tail, recorded to the nearest centimeter on a wide measuring board with the first centimeter space offset a half-centimeter from the headboard.

Regression lines were computed by the method of least squares and the formulae of Zar (1974) were used to calculate the slopes and the intercepts for each of the relationships between fish length and egg capsule dimensions. Pairs of regression lines were compared by covariance analysis (Snedecor and Cochran, 1967).

\section{Results}

The egg capsule, its development and contents

Development of egg capsule. Various authors differ regarding the use of the terms "anterior" and 


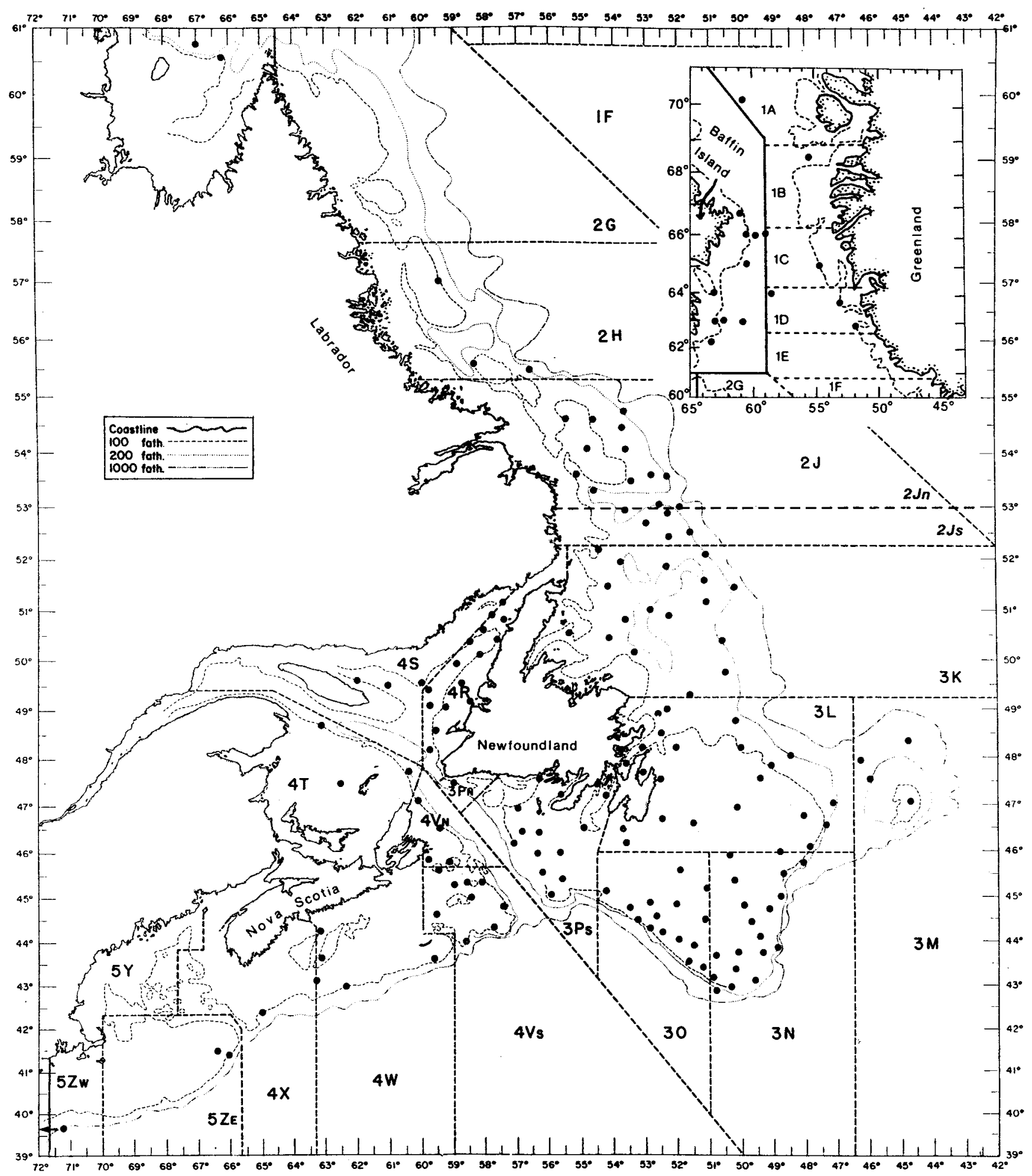

Fig. 1. Map of Northwest Atlantic showing locations of skate samples and the NAFO divisions mentioned in the text.

"posterior" in relation to the egg capsule. The young skate emerges from the posterior part of the capsule in relation to the parent fish, and this part is called "anterior" by some authors. It is less confusing, however, if the terms "anterior" and "posterior" are applied, as in this paper, to the capsule as it occurs in the oviduct of the female.

The posterior horns of the egg capsule develop first, growing from the left and right corners of the deep 

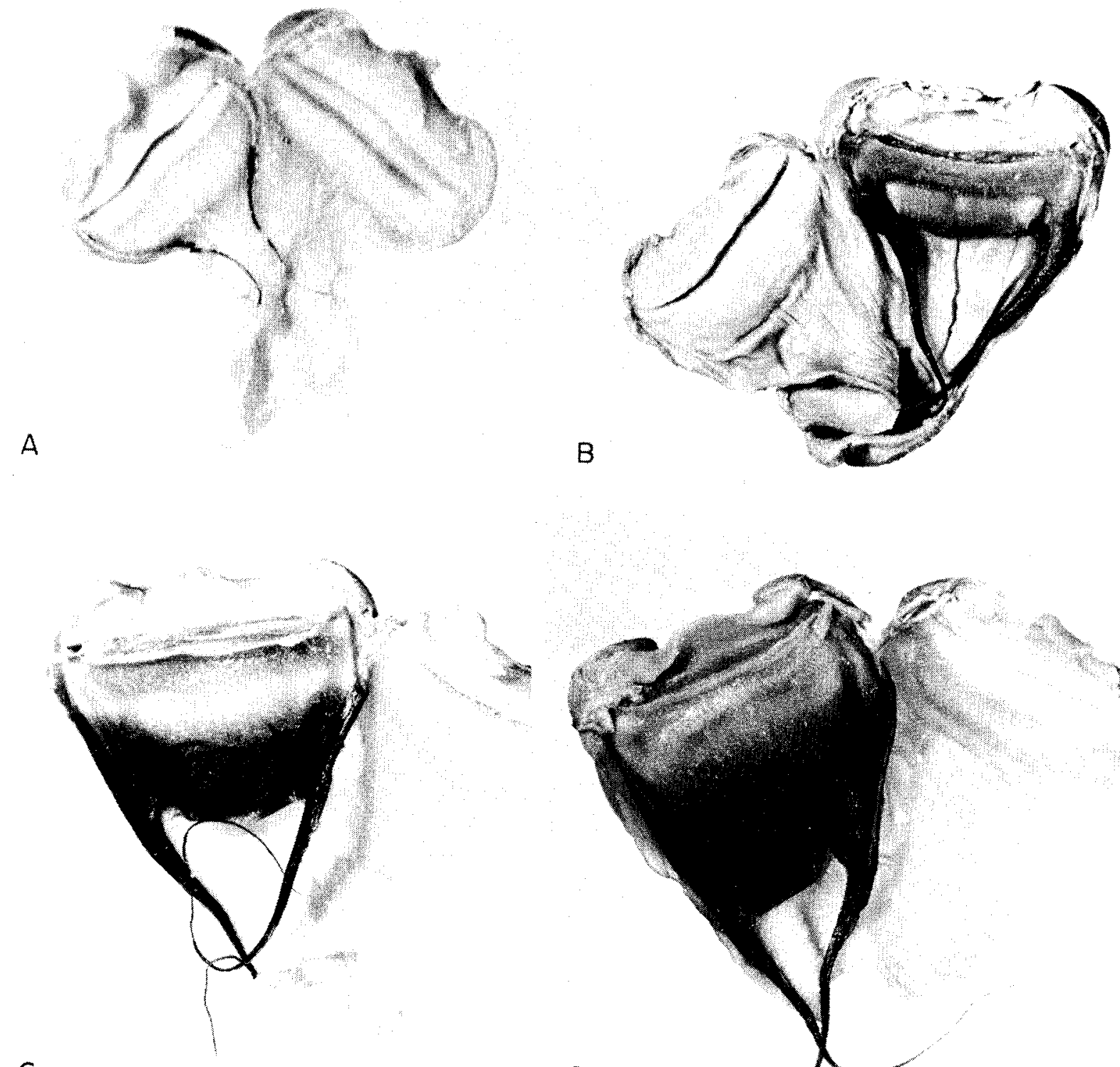

C

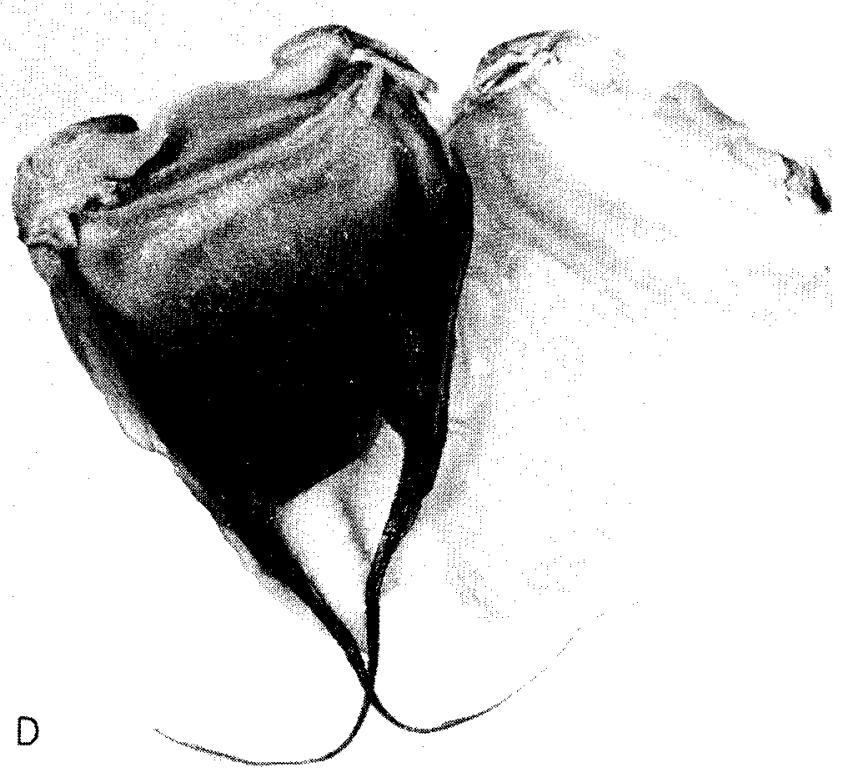

Fig. 2. Development of egg capsule in relation to shell gland and oviduct of thorny skate. A, posterior horns beginning to form; B, capsule about one-eighth complete, posterior horns and posterior fringe and body of capsule forming posterior to the transverse sulcus of shell gland; $C$, capsule about one-quarter complete; $D$, capsule about one-half complete. (The developing capsule is shown in its normal position. resting on one side of the shell gland, with the shell gland cut longitudinally to show all or part of the other half of the shell gland and oviduct. All about 0.6 of normal size.)

transverse sulcus of the shell gland (Fig. 2A). The posterior fringe of the capsule is next formed, evidently from the part of the shell gland posterior to the transverse sulcus (Fig. 2B). As the capsule develops posterior to the transverse sulcus, open anteriorly and closed posteriorly (Fig. 2C, D, E), albumen is secreted into the capsule, evidently from the portion of the shell gland anterior to the transverse sulcus. Two mature eggs are normally liberated from the ovaries, an egg entering the ostium of each Fallopian tube (the part of the oviduct anterior to the shell gland) and being fertilized as it passes down the tube toward the open capsule in the shell gland. The posterior parts of the developing capsule are brownish or greenish and harden gradually, and the anterior parts are whiter and soft. The capsule continues to grow and the anterior 

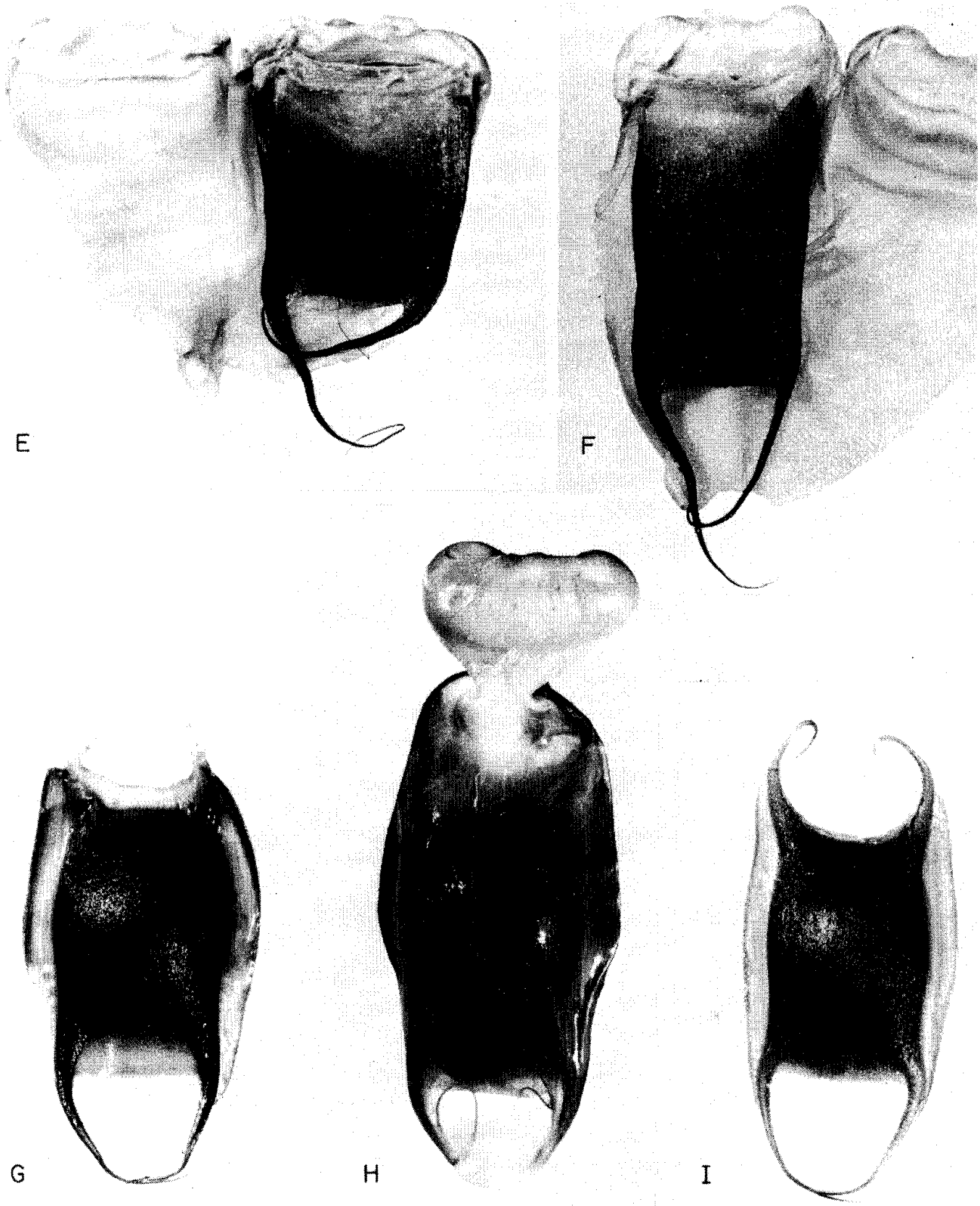

Fig. 2. (continued). E, capsule about three-quarters complete; $F$, body of capsule almost complete but not closed anteriorly and anterior horn not formed; G, body of capsule completed and closed anteriorly but anterior horns incomplete (lateral keel broken at posterior left capsule); $\mathrm{H}$, capsule in dorsal view, greatest curvature, completely formed and lying in oviduct immediately posterior to the shell gland; complete capsule before extrusion. (All about 0.6 of normal size.) 
parts harden after it is sealed off anteriorly, the shorter anterior horns being the last parts to be completed (Fig. 2F, G, 1). Normally, the completed capsule within the skate is found in the oviduct immediately posterior to the shell gland (Fig. 2H). The surfaces of the capsule are convex dorsally and rather flat ventrally. At extrusion, the capsule is covered with a felted mass of fibers, described by Clark (1926).

Passage of egg into egg capsule. Two fish, with only the posterior horns and none of the main body of the egg capsule developed, had no eggs in the Fallopian tubes (Table 1). There were no eggs in the cap- sules of 18 specimens examined with capsules one-quarter and one-half completed, but an egg was present in each of the Fallopian tubes of 16 fish. In the two exceptions, there was an egg in the left but not the right Fallopian tube. Three of eight fish with capsules about three-quarters completed had an egg in each Fallopian tube and none in the capsules, and vice versa for four specimens; in one fish, the eggs were partly in the Fallopian tubes and partly in the capsules. Of 13 specimens with nearly complete capsules, 11 had the eggs in the capsules, 1 had an egg in each Fallopian tube, and 1 had an egg in the left Fallopian tube and an egg in the right capsule. In addition to the specimens

TABLE 1. Passage of eggs of thorny skate into egg capsules in relation to stage of development of incomplete capsules in shell glands and oviducts. (The median length of the capsule includes the velum. The median length of the complete capsule corresponding to the length of the female parent was estimated from Fig. 3.)

\begin{tabular}{|c|c|c|c|c|c|c|c|}
\hline $\begin{array}{c}\text { Capsule } \\
\text { completion } \\
\text { stage }^{\mathrm{a}}\end{array}$ & $\begin{array}{c}\text { Capsule } \\
\text { median } \\
\text { length } \\
(\mathrm{mm}) \\
\end{array}$ & $\begin{array}{l}\text { Eggs in } \\
\text { Fallopian } \\
\text { tubes }\end{array}$ & $\begin{array}{c}\text { Eggs } \\
\text { in } \\
\text { capsules }\end{array}$ & $\begin{array}{c}\text { Volume } \\
\text { of egg } \\
(\mathrm{ml})\end{array}$ & $\begin{array}{c}\text { Volume of } \\
\text { albumen } \\
(\mathrm{ml})\end{array}$ & $\begin{array}{l}\text { Length of } \\
\text { female } \\
\text { parent } \\
\text { (cm) }\end{array}$ & $\begin{array}{c}\text { Estimated } \\
\text { median length } \\
\text { of complete } \\
\text { capsule }(\mathrm{mm})\end{array}$ \\
\hline 0 & 0 & no & no & - & - & 75 & 82 \\
\hline 0 & 0 & no & no & - & - & 78 & 84 \\
\hline $1 / 4$ & 10 & yes & no & - & - & 75 & 82 \\
\hline $1 / 4$ & 20 & yes & no & - & - & 59 & 72 \\
\hline $1 / 4$ & 25 & yes & no & - & 1.5 & 85 & 88 \\
\hline $1 / 4$ & 25 & yes & no & - & present & 88 & 90 \\
\hline $1 / 4$ & 27 & yes $^{b}$ & no & - & 1.5 & 77 & 83 \\
\hline $1 / 4$ & 28 & yes & no & - & ca. 2-3 & 71 & 80 \\
\hline $1 / 4$ & 30 & yes & no & - & - & 78 & 84 \\
\hline $1 / 2$ & - & yes & no & - & 3.0 & 56 & 71 \\
\hline $1 / 2$ & - & yes $^{b}$ & no & - & present & 71 & 80 \\
\hline $1 / 2$ & - & yes & no & - & present & 79 & 84 \\
\hline $1 / 2$ & - & yes & no & - & present & 84 & 87 \\
\hline $1 / 2$ & 37 & yes & no & - & - & 70 & 79 \\
\hline $1 / 2$ & 42 & yes & no & - & present & 74 & 81 \\
\hline $1 / 2$ & 42 & yes & no & - & present & 75 & 82 \\
\hline $1 / 2$ & 43 & yes & no & - & - & 69 & 78 \\
\hline $1 / 2$ & 46 & yes & no & - & 6 & 83 & 87 \\
\hline $1 / 2$ & 46 & yes & no & - & - & 85 & 88 \\
\hline $1 / 2$ & 48 & yes & no & - & 7.4 & 80 & 85 \\
\hline $3 / 4$ & - & no & yes & - & present & 75 & 82 \\
\hline $3 / 4$ & - & no & yes & 8.6 & 11.2 & 80 & 85 \\
\hline $3 / 4$ & 55 & partly & partly & - & present & 74 & 81 \\
\hline $3 / 4$ & 57 & no & yes & 7.0 & 9.0 & 57 & 71 \\
\hline $3 / 4$ & 60 & no & yes & - & present & 76 & 83 \\
\hline $3 / 4$ & 65 & yes & no & - & present & 82 & 86 \\
\hline $3 / 4$ & 66 & yes & no & - & - & 80 & 85 \\
\hline $3 / 4$ & 67 & yes & no & - & 7.9 & 82 & 86 \\
\hline 1 & - & - & yes & 9.8 & 13.6 & 76 & 83 \\
\hline 1 & - & - & yes & - & - & 78 & 84 \\
\hline 1 & 60 & - & yes & - & - & 51 & 68 \\
\hline 1 & 74 & yes $^{b}$ & yes $^{c}$ & - & - & 71 & 80 \\
\hline 1 & 75 & - & yes & 8.0 & 11.6 & 73 & 81 \\
\hline 1 & 76 & yes & no & - & - & 71 & 80 \\
\hline 1 & 76 & - & yes & 10.8 & 16.7 & 74 & 81 \\
\hline 1 & 79 & - & yes & 10.5 & 12.1 & 75 & 82 \\
\hline 1 & 80 & - & yes & 9.1 & 10.1 & 71 & 80 \\
\hline 1 & 81 & - & yes & - & - & 66 & 77 \\
\hline 1 & 83 & -- & yes & 12.3 & 11.6 & 74 & 81 \\
\hline 1 & 86 & - & yes & 12.3 & 12.0 & 76 & 83 \\
\hline 1 & 94 & - & yes & 10.1 & 12.7 & 80 & 85 \\
\hline
\end{tabular}

${ }^{a}$ Completion stages: $0=$ posterior horns only; $1 / 4=1 / 8-<3 / 8 ; 1 / 2=3 / 8-<5 / 8 ; 3 / 4=5 / 8-<7 / 8 ; 1=7 / 8-$ capsule closed but not complete anteriorly.

beft tube only. ${ }^{c}$ Right capsule only 
listed in Table 1, a new egg was found in the Fallopian tube of each of two fish with complete capsules containing eggs. In one mature female, there was no trace of capsules in the oviducts but an egg was found in each Fallopian tube. Albumen appears to be secreted as soon as the capsule is large enough to hold it and continues to be secreted until the capsule reaches its full size and is closed (Table 1).

Abnormal egg capsules. In most of the specimens examined with nearly complete to fully complete capsules containing eggs, the capsules and the eggs of each pair were approximately similar in size. However, in three specimens with complete capsules ready for extrusion, one capsule of each pair did not contain an egg, and the pair of capsules in an $85-\mathrm{cm}$ fish contained one normal and one unusually small egg (Table 2). Although the quantity of albumen in the capsules with no eggs was slightly greater than in those with normal eggs, the excess was much less than the expected volume of the missing egg. However, for each specimen, the difference in the weight of the capsule approximated the volume of the missing egg or egg material, and the abnormal capsules had slightly smaller linear dimensions.

Extrusion of egg capsules. Both complete capsules were usually found in the oviducts immediately posterior to the shell glands, indicating that the capsules are probably retained in this position until extrusion occurs. However, in 10 females observed by the author to possess only one complete capsule, it was always in the left oviduct, the right capsule having been recently extruded, as indicated by the extended and blood-suffused portion of the oviduct posterior to the shell gland.

\section{Seasonal and geographical distribution of skates with egg capsules}

Egg capsules in various stages of development (appearance of posterior horns to fully formed capsules ready for extrusion) were observed in 169 thorny skates from various areas of the Northwest Atlantic, and $65 \%$ (range $60-69 \%$ by season) of these were complete and ready for extrusion (Table 3). Complete and incomplete capsules were observed in every month throughout the year. Because some complete capsules, but not usually incomplete ones, are lost from the females between capture by the trawl and examination of the specimens, the percentages of females observed with complete capsules are minimal.

The samples of thorny skates taken in areas from Iceland, West Greenland (Div. 1BCD) and Baffin Island (Div. OAB) southward to the Scotian Shelf (Div. 4VWX) included 764 females which were classified as mature, of which 169 specimens (noted above) contained egg capsules in various stages of completion (Table 4). The lack of data for some areas and seasons precludes spatial and seasonal comparison of the proportions of mature females producing capsules. However, by combining the data for the Grand Bank and St. Pierre

TABLE 2. Comparative measurements of left and right egg capsules and their contents in four female thorny skates with abnormal pairs of capsules.

\begin{tabular}{|c|c|c|c|c|c|c|c|c|}
\hline \multirow[b]{2}{*}{ Capsule parameter } & \multicolumn{2}{|c|}{$48-\mathrm{cm}$ fish } & \multicolumn{2}{|c|}{$64-\mathrm{cm}$ fish } & \multicolumn{2}{|c|}{$81-\mathrm{cm}$ fish } & \multicolumn{2}{|c|}{$85-\mathrm{cm}$ fish } \\
\hline & Left & Right & Left & Right & Left & Right & Left & Right \\
\hline Weight (g) & - & - & 47 & 36 & 40 & 50 & 55 & 45 \\
\hline Median length ( $\mathrm{mm}$ ) & 65 & 67 & 74 & 72 & 73 & 77 & 73 & 73 \\
\hline Greatest width (mm) & 47 & 45 & 65 & 62 & 62 & 63 & 74 & 73 \\
\hline \multicolumn{9}{|l|}{ Width excluding } \\
\hline lateral keels $(\mathrm{mm})$ & - & - & - & - & - & - & 54 & 50 \\
\hline Greatest depth ( $\mathrm{mm}$ ) & 一 & - & - & - & - & - & 25 & 24 \\
\hline Egg volume $(\mathrm{ml})$ & broken & 0 & 9.0 & 0 & 0 & 11.0 & 12.9 & 3.5 \\
\hline Albumen volume $(\mathrm{mi})$ & - & 5.1 & 12.9 & 13.1 & 15.2 & 12.8 & 16.1 & 13.8 \\
\hline
\end{tabular}

TABLE 3. Seasonal distribution of female thorny skates with egg capsules in various stages of completion.

\begin{tabular}{|c|c|c|c|c|c|c|c|c|}
\hline \multirow[b]{2}{*}{ Season } & \multicolumn{7}{|c|}{$\begin{array}{c}\text { Number of skates with capsules in various } \\
\text { stages of development }\end{array}$} & \multirow{2}{*}{$\begin{array}{c}\text { Percent } \\
\text { fully } \\
\text { complete }\end{array}$} \\
\hline & 0 & $1 / 4$ & $1 / 2$ & $3 / 4$ & 1 & $F$ & Total & \\
\hline Jan-Mar & 2 & 3 & 3 & 1 & 4 & 29 & 42 & 69.0 \\
\hline Apr-Jun & 1 & 2 & 4 & 1 & 4 & 25 & 37 & 67.6 \\
\hline Jul-Sep & 3 & 3 & 6 & 6 & 4 & 33 & 55 & 60.0 \\
\hline Oct-Dec & 6 & 1 & 1 & 2 & 2 & 23 & 35 & 65.7 \\
\hline Total & 12 & 9 & 14 & 10 & 14 & 110 & 169 & 65.1 \\
\hline$\%$ & 7.1 & 5.3 & 8.3 & 5.9 & 8.3 & 65.1 & 100 & \\
\hline
\end{tabular}

a Stages $0-1$ same as in Table $1 ; F=$ fully formed capsule ready for extrusion. 
TABLE 4. Percentage distribution of mature female thorny skates with developing or complete egg capsules by season and area.

\begin{tabular}{|c|c|c|c|c|c|c|}
\hline \multirow[b]{2}{*}{ Area } & \multirow{2}{*}{$\begin{array}{c}\text { Length } \\
\text { range } \\
(\mathrm{cm}) \\
\end{array}$} & \multicolumn{5}{|c|}{$\begin{array}{l}\text { Percentage of mature female skates with capsules } \\
\text { (Total number of matures in parentheses) }\end{array}$} \\
\hline & & Jan-Mar & Apr-Jun & Jul-Sep & Oct-Dec & Jan-Dec \\
\hline Iceland $+18 C D$ & $45-64$ & - & - & $22(18)$ & - & $22(18)$ \\
\hline $0 A-2 J n$ & $40-59$ & - & $33 \quad(9)$ & $27(33)$ & - & $29(42)$ \\
\hline $2 J s-3 K$ & $45-79$ & - & $20(10)$ & $32 \quad(34)$ & $25 \quad$ (4) & $29(48)$ \\
\hline $3 \mathrm{~L}$ & $60-89$ & $11 \quad(9)$ & $20(40)$ & $16 \quad(67)$ & $8(64)$ & $14(180)$ \\
\hline $3 N$ & $60-94$ & $0 \quad(4)$ & $19(31)$ & $16 \quad(75)$ & $30(70)$ & $22(180)$ \\
\hline 30 & $65-94$ & $45 \quad(78)$ & $44 \quad(27)$ & $0 \quad(1)$ & - & $44(106)$ \\
\hline $3 P s$ & $60-89$ & $25(20)$ & $22(27)$ & $30(10)$ & $0 \quad$ (4) & $23(61)$ \\
\hline 4RST & $45-74$ & $6(16)$ & - & $6 \quad(87)$ & $28 \quad(18)$ & $9(121)$ \\
\hline $4 V W X$ & $60-89$ & - & $0 \quad$ (2) & - & $50 \quad(6)$ & $38 \quad(8)$ \\
\hline Ali areas & $40-94$ & $33(127)$ & $25(146)$ & $17(325)$ & $21(166)$ & $22(764)$ \\
\hline
\end{tabular}

Bank (i.e. Div. 3LNOPS), the percentages of mature females with capsules were highest in the early part of the year $(37,26,17$ and $19 \%$ in quarters $1-4$ respectively). In the western part of the Labrador Sea, the most northerly specimen with two complete capsules was obtained at the mouth of Ungava Bay, but thorny skates with developing capsules and many thorny skate capsules from the sea bottom were taken farther north off Baffin Island (Div. OAB).

\section{Fish length and egg capsule dimensions}

Length and width of capsule. Both the median length and greatest width of complete egg capsules of female thorny skates increased with fish length (Fig. 3), and highly significant correlations were indicated by the corresponding correlation coefficients ( $r$ ). It is also clearly evident that capsule dimensions for areas with sexual maturity beginning and occurring at greater fish lengths were greater than those for areas with sexual maturity beginning and occurring at smaller lengths. The only significant overlap of the two groups with respect to fish length occurred for a $73-\mathrm{cm}$ fish taken in the southern part of Div. $4 \mathrm{R}\left(48^{\circ} 15^{\prime} \mathrm{N}, 59^{\circ} 44^{\prime} \mathrm{W}\right)$, adjacent to an area (Div. 3P) where maturity occurs at greater fish lengths. The slopes and intercepts of the regression lines for the data from areas with smaller and greater fish lengths at sexual maturity were not significantly different, and one regression line was considered appropriate for each of the relationships between fish length and capsule dimensions (Fig. 3).

Weight of capsule and volume of contents. There were no significant differences in slopes and intercepts of regression lines fitted to logarithmically transformed data for fish length relative to egg and albumen volumes and capsule weights of the left and right capsules, and the variances were homogeneous. Data for left and right capsules were therefore averaged to produce one data point per fish for each relationship (Fig. 4). The resulting regression lines showed good relationships between fish length and the three capsule parameters, highly significant correlations being indi-

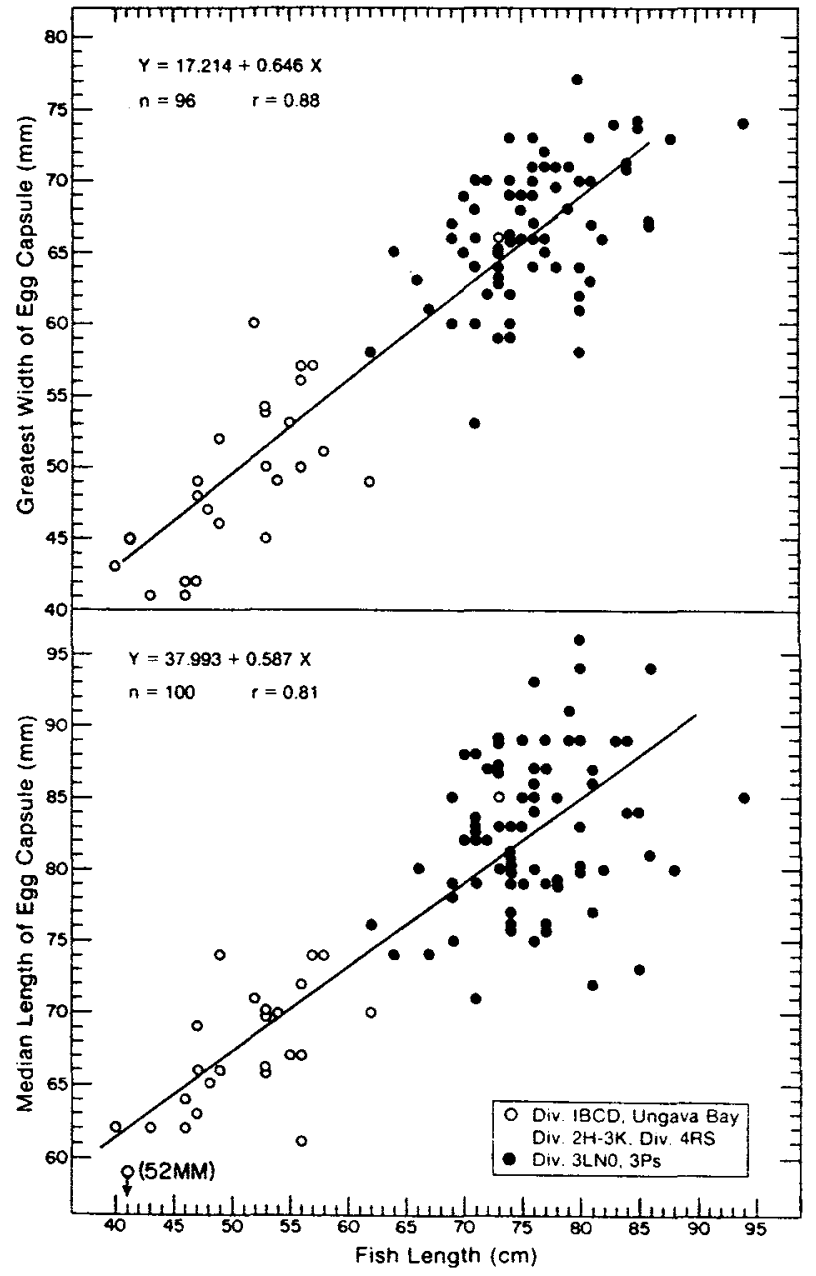

Fig. 3. Median length and greatest width of complete egg capsules of mature female thorny skates in relation to total length of fish.

cated by the $r$ values. The slope of the line for capsule weight was slightly greater than that for albumen volume and both were much greater than that for egg volume. 


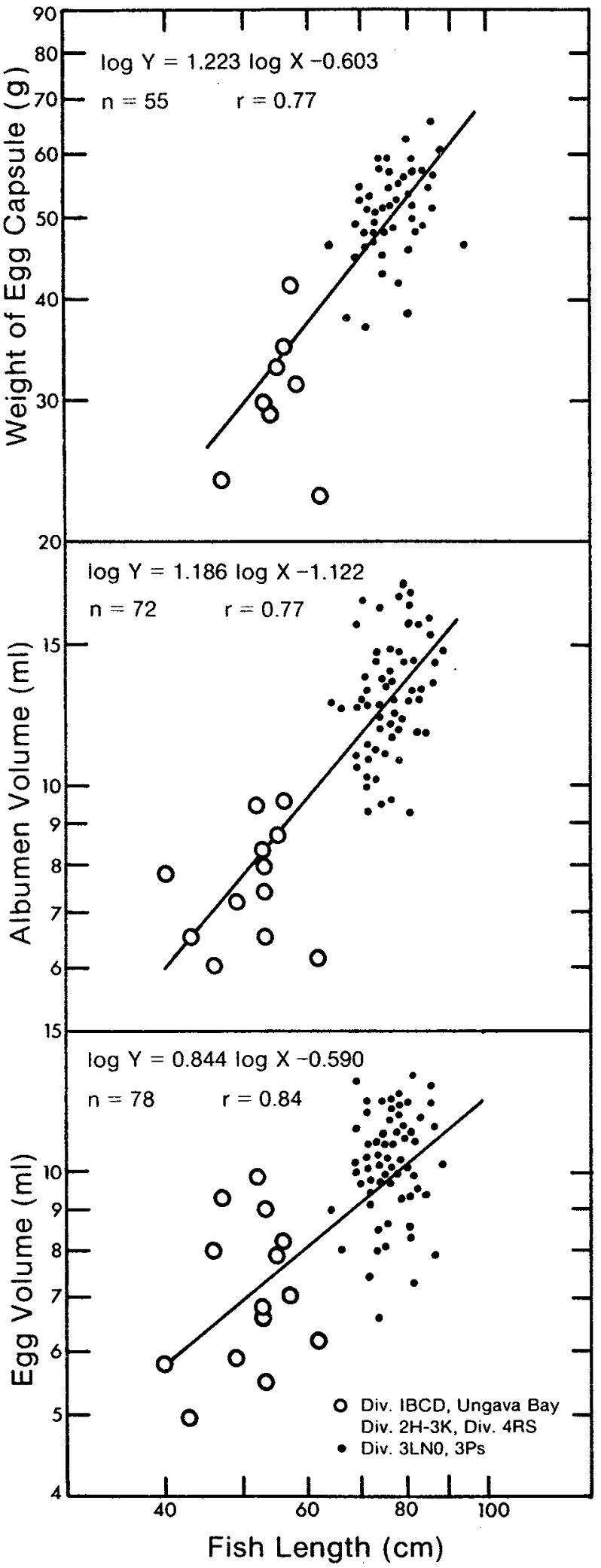

Fig. 4. Egg volume, albumen volume, and weight of egg capsules of mature female thorny skates in relation to total length of fish. (Data relate to actual values plotted on $\log _{10}$ scales.)
As would be expected from the relationships of length and width of egg capsule to fish length (Fig. 3), the egg and albumen volumes and the capsule weight were less in areas where sexual maturity occurred at smaller fish sizes (Fig. 4).

\section{Discussion}

Metten (1939) described and illustrated the posterior shell-secreting and the anterior albumensecreting zones of the shell gland of the dogfish, Scyliorhynus canicula. Similarly, from observations on the developing egg capsule of $R$. radiata described in this paper, it is evident that the shell gland posterior to the transverse sulcus secretes the capsule and that the zone anterior to the transverse sulcus produces the albumen. Hobson (1930) described and illustrated for $R$. radiata the posterior "half" of an egg capsule situated in the posterior part of the shell gland but containing no egg. A similar (but abbreviated and not illustrated) description of the development of the capsule to that in this paper was reported for Raja eglanteria and Raja erinacea by Fitz and Diaber, (1963). In $R$. erinacea, ovulation from each ovary occurs when the capsule is approximately one-quarter to one-half formed (Richards et al., 1963). Ovulation in $R$. radiata should occur under similar circumstances or possibly a little earlier, as the eggs were passing down the Fallopian tubes in one specimen with the capsule oneeighth complete and in all seven fish with the egg capsule less than three-eighths complete (Table 1). Fitz and Daiber (1963) reported that the fertilized egg of $R$. eglanteria flows into the capsule when the latter is two-thirds formed. Metten (1939) found that no eggs were present in the egg capsules of $S$. canicula when the capsules were less than three-quarters completed. This is approximately similar to the results for $R$. radiata (Table 1), where the median lengths of the developing capsules containing eggs were seven-tenths or more of the estimated lengths of the complete capsules. The formation of the complete egg capsule in $R$. erinacea off northeastern United States takes a minimum of 48 hours (Richards et al., 1963), but the time required for $R$. radiata of the Newfoundland area may be greater because of the lower water temperatures.

Occasional egg capsules without eggs, as recorded for $R$. radiata in this paper, have been reported for various elasmobranchs by many authors, e.g. Beard (1890) for R. radiata and Raja batis in European waters, Clark (1922) for European skates, Metten (1939) for Scyliorhynus canicula, Templeman (1944) for Squalus acanthias and Richards et al. (1963) for $R$. erinacea. From the data for $R$. radiata on the passage of eggs through the Fallopian tubes into the capsule (Table 1), it appears that an egg could sometimes be 
too late in passing down the Fallopian tube to reach the capsule before it closed. However, Richards et al. (1963) found that one ovary in R. erinacea often contained only small eggs and the other had ripe ones, and that, in these specimens, the capsule in the oviduct on the same side as the unripe eggs was empty. Whenever it was mentioned by an author, albumen was invariably present in the complete capsule, as in the present study of $R$. radiata.

No capsules with more than one egg were found in this study of $R$. radiata. However, Richards et al. (1963) found two eggs in a single capsule of $R$. erinacea on two occasions and four eggs in a capsule in one instance, but the other capsule in each of these specimens did not contain an egg.

It is evident that the right capsule is extruded before the left capsule in $R$. radiata, as the left capsule was always the one remaining, from the author's observations of 10 thorny skate with only one fully developed capsule remaining in the oviducts. In $R$. erinacea, the right capsule was laid slightly in advance of the left, the latter being laid first in only two out of 6,000 spawning females observed by Richards et al., (1963). Also for Raja garmani off Delaware and North Carolina, in four females with only one egg capsule, this was always in the left uterus (McEachran, 1970).

In the present sutdy of thorny skate, there was evidence that egg capsule development and presumably capsule extrusion occurred in every month of the year, but such evidence was mainly for the Grand Bank and St. Pierre Bank areas (Table 4). For these areas, the percentage of females with capsules was highest in January-March and next highest in April-June, but these percentages are greatly influenced by the data for the southwestern Grand Bank (Div. 30) for which little or no data were available in the remaining seasons. Definitive conclusions on this matter must await more systematic collections in the various seasons. The principal spawning (capsule extrusion) periods of $R$. erinacea from the southern New England area were reported by Richards et al. (1963) to be NovemberJanuary and June-July, although females with capsules were caught throughout the year. McEachran (1970) found egg capsules in female R. garmani during all seasons of the year but they were significantly more numerous in summer.

There is some information in the literature indicating possible differences in size of egg capsules and consequently in size of female $R$. radiata at maturity, but it is usually uncertain how the capsule measurements were taken and some of the data pertain to capsules taken from the sea bottom. Such capsules will have lost most of the velum and their lengths will usually be less than those of fresh specimens. The smallest capsules of $R$. radiata were reported from the North Sea, averaging $48 \mathrm{~mm}$ long and $34 \mathrm{~mm}$ wide with the smallest being $42 \times 25 \mathrm{~mm}$ (Clark, 1926). Nine capsules of this species from Trondhjem Fjord, evidently from the sea bottom, were $50-65 \mathrm{~mm}$ long and $40-48 \mathrm{~mm}$ wide (Nordgaard, 1917). Thorny skate capsules from West Greenland were 44-66 mm long, a pair obtained from a female being 66 and $68 \mathrm{~mm}$ long (Jensen, 1914), and specimens from the sea bottom near the Labrador coast were $55-70 \mathrm{~mm}$ long and $40-50 \mathrm{~mm}$ wide (Backus, 1957). Two capsules of $R$. radiata from the southern Gulf of St. Lawrence sea bottom were 66-68 $\mathrm{mm}$ long and $48-49 \mathrm{~mm}$ wide, and eight capsules taken from females from the outer coast of Nova Scotia were 77-90 mm long and 58-73 mm wide (Vladykov, 1936). A single capsule of $R$. radiata from an $81-\mathrm{cm}$ female on Georges Bank was $76 \times 57 \mathrm{~mm}$ (Bigelow and Schroeder, 1953). In this paper, the median lengths of thorny skate egg capsules were 61-74 mm and 71-96 $\mathrm{mm}$ for the northern and southern regions of the Northwest Atlantic respectively, and the corresponding widths were $41-60 \mathrm{~mm}$ and $53-77 \mathrm{~mm}$.

It is apparent from the data presented in this paper that the size of egg capsules of $R$. radiata increased with increased length of females and that the capsules were, on the average, smaller in mature fish from areas such as Labrador and West Greenland where sexual maturity begins and occurs at smaller fish sizes than from areas such as the Grand Bank and St. Pierre Bank where the fish grow to and sexual maturity occurs at larger sizes.

\section{Acknowledgements}

I am grateful to E. M. LeGrow who assisted in gathering much of the material used in this study and to $S$. H. Lee and J. V. Arklie for much assistance in assembling the data. E. L. Rowe was responsible for the photographs.

\section{References}

BACKUS, A. H. 1957. The fishes of Labrador. Bull. Am. Mus. Nat. Hist., 113: $275-337$

BEARD, J. 1890 . On the development of the common skate (Raja batis). Eighth Ann. Rep. Fish. Bd. Scot. for 1889, Part III, Sci. Invest., p. 300-311.

BIGELOW, H. B., and W. C. SCHROEDER. 1953. Fishes of the western North Atlantic. Sawfishes, guitarfishes, skates and rays. Mem. Sears Fdn. Mar. Res., 1(2): 1-514.

CLARK, R. S. Rays and skates (Raiae) I. Egg-capsules and young. $J$. Mar. Biol. Assoc. U. K., 12 (n.s.): 577-643.

1926. Rays and skates. A revision of the European species Fish. Bd. Scot., Sci. Invest. 1926, No. 1: 1-66.

FITZ, E. S., and F. C. DAIBER. 1963. An introduction to the biology of Raja eglanteria Bose 1802 and Raja erinacea Mitchill 1825 as they occur in Delaware Bay. Bull. Bingham Oceanogr. Coll., 18(3): 69-97.

HOBSON, A. D. 1930. A note on the formation of the egg-case of the 
skate. J. Mar. Biol. Assoc. U. K., 16: 577-581.

JENSEN, A. S. 1914. The selachians of Greeniand. Mindeskr. for Jap. Steenstrup, Kobenhavn, 2, No. 30: 1-40.

1948. Contributions to the ichthyofauna of Greenland 8-24. Spolia Zool. Mus. Hauniensis, Skrift. Univ. Zool. Mus. Kobenhavn, 9: 3-182.

MCEACHRAN, J. D. 1970. Egg capsules and reproductive biology of the skate Raja garmani (Pisces: Rajidae). Copeia, 1970 (1): 197199.

METTEN, H. 1939. Studies on the reproduction of the dogfish. Philos. Trans. R. Soc. Lond. (B Biol. Sci.), 230: 217-238.

NORDGAARD, O. 1917. Contributions to the life history of the fishes in Trondhjem Fjord and environs. Det Kgl. Norske Videns. Selskabs Skrift. 1915, 9: 1-38

RICHARDS, S. H., D. MERRIMAN, and L. H. CALHOUN. 1963. Studies on the marine resources of southern New England. IX. The biology of the Little skate, Raja erinacea Mitchill. Bull. Bingham Oceanogr. Coll., 18 (3) : 4-67.

SNEDECOR, G. W., and W. G. COCHRAN. 1967. Statistical methods (sixth ed.), lowa State Univ. Press, Ames, lowa, U. S. A., 593 p.

TEMPLEMAN, W. 1944. The life-history of the spiny dogfish (Squalus acanthias) and the Vitamin A values of dogfish liver oil. Res. Bull., Dept. Natural Resources, Nfld., 15, 102 p.

VLADYKOV, V. D. 1936. Capsules d'oeufs de raies de l'Atlantique Canadien appartenant au genre Raja. Bull. Nat. Canadien, 63: 211-231.

WILLIAMSON, H. C. 1913. On the eggs of certain skates (Raja). Fish. Bd. Scot. Sci. Invest. 1912, No. 1: 1-6.

ZAR, J. H. 1974. Biostatistical analysis. Prentice-Hall, Englewood Cliffs, N. J., 620 p. 